\title{
Relações estabelecidas entre idosos e familiares em estado de corresidência
}

\author{
Talita Santos Oliveira Sampaio \\ Lucas Silveira Sampaio \\ Claudia Ribeiro Santos Lopes \\ Hernane Borges de Barros Pereira \\ Alba Benemérita Alves Vilela
}

\section{SciELO Books / SciELO Livros / SciELO Libros}

SAMPAIO, T. S. O., SAMPAIO, L. S., LOPES, C. R. S., PEREIRA, H. B. B., and VILELA, A. B. A. Relações estabelecidas entre idosos e familiares em estado de corresidência. In: D'ALENCAR, R. S., ed. A representação social na construção da velhice [online]. Ilhéus, BA: EDITUS. 2017, pp. 215-237. ISBN: 978-85-7455-486-0. https://doi.org/10.7476/9788574554860.0011.

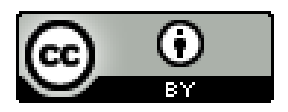

All the contents of this work, except where otherwise noted, is licensed under a $\underline{\text { Creative }}$ Commons Attribution 4.0 International license.

Todo o conteúdo deste trabalho, exceto quando houver ressalva, é publicado sob a licença Creative Commons Atribição 4.0.

Todo el contenido de esta obra, excepto donde se indique lo contrario, está bajo licencia de la licencia Creative Commons Reconocimento 4.0. 


\section{RELAÇÕES ESTABELECIDAS ENTRE IDOSOS E FAMILIARES EM ESTADO DE CORRESIDÊNCIA}

Talita Santos Oliveira Sampaio

Lucas Silveira Sampaio

Claudia Ribeiro Santos Lopes

Hernane Borges de Barros Pereira

Alba Benemérita Alves Vilela

\section{O envelhecimento populacional e a família}

O envelhecimento populacional no Brasil ocorre de forma radical e bastante acelerada. Essa velocidade do processo de transição demográfica e epidemiológica traz uma série de desafios para gestores e pesquisadores dos sistemas de saúde, com repercussões para toda a sociedade, principalmente quando se leva em consideração o atual contexto social do país marcado por acentuada desigualdade social, pobreza e fragilidade das instituições (VERAS, 2009).

$\mathrm{O}$ processo de envelhecimento tem provocado diversas mudanças na estrutura social do mundo, com alterações nas relações sociais e produtivas, na saúde, nos setores econômicos e habitacionais, distribuição de renda e enfaticamente nas famílias (AGUIAR, 2007; PAULO; WAJNMAN; OLIVEIRA, 2013). Dentre essas mudanças, podese destacar o fato de o crescimento da população idosa 
ter sido acompanhado pela redução das capacidades tanto físicas como cognitivas dos idosos, determinando diferentes graus de dependência, o que pode favorecer ao maior convivio e necessidade de suporte familiar. Neste contexto, o envelhecimento leva a transformações relacionadas às famílias, o que contribui para o aumento do número de estudos que enfoquem a família e suas relações com seus membros idosos (TORRES et al., 2010).

Além disto, pode-se salientar que as mudanças ocorridas nas famílias também sofrem repercussões decorrentes da autonomia feminina, alterações no mercado de trabalho, dependência maior dos filhos e pela legalização e aceitação social de separações e divórcios. Neste sentido, a família não pode ser vista como uma entidade estática, visto que, cada vez mais, busca criar um modo de viver de características próprias numa estrutura dinâmica e contínua (LEONE; MAIA; BALTAR, 2010).

A família é vista como a base para garantir o sustento, o desenvolvimento e a proteção de seus membros, independentemente da forma como ela está estruturada. Em relação aos idosos, historicamente, a família é a principal fonte de apoio e cuidado (MONTEIRO; SENA, 2012). Segundo o Estatuto do Idoso, criado em 2003, é obrigação da família, da comunidade, da sociedade e do Poder Público assegurar ao idoso, com absoluta prioridade, a efetivação do direito à vida, à saúde, à alimentação, à educação, à cultura, ao esporte, ao lazer, ao trabalho, à cidadania, à liberdade, à dignidade, ao respeito e a convivência familiar e comunitária (BRASIL, 2003).

O seio familiar também é considerado um sistema de saúde para os idosos, visto que, possui um conjunto de conhecimentos e práticas que guiam suas ações na promoção da saúde, na prevenção e no tratamento de doenças. Esse suporte contribui de maneira importante para a saúde física e psicológica do indivíduo, entretanto, seu efeito é tido como benéfico, se executado pelos membros da família de 
forma satisfatória. Sendo assim, compreende-se ser fundamental para o planejamento assistencial adequado ao idoso a compreensão de seu contexto familiar, compreendendo as questões que envolvem o convivio e a dinâmica de relações dos idosos e seus familiares (TORRES et al., 2010).

Ressalta-se que essas transformações na família associadas ao envelhecimento fizeram surgir diferentes arranjos familiares presentes na sociedade, com destaque para a família intergeracional, onde o idoso convive com múltiplas gerações no mesmo espaço domiciliar, ou seja, o estabelecimento da corresidência (CAMARANO et al., 2004). Essa convivência garante ainda o conhecimento cultural, bem como desenvolve diversas trocas que contribuem para assegurar a reprodução social (JEDE; SPULDARO, 2009).

Neste contexto, a família é tida como uma rede de suporte social aos idosos, referendada pelas politicas públicas deste país. Desta forma, faz-se necessário o apoio às famílias, dando condições para que elas exerçam o seu papel de provedoras de cuidados aos seus idosos. Além disso, esta família precisa de uma maior assistência, sendo mais valorizada e cuidada.

\section{Corresidência entre idosos e familiares}

Corresidência, segundo Vilela et al. (2013, p. 53), trata-se de "arranjo social de coabitação, no qual duas ou mais pessoas, independentemente da geração, gênero ou nivel de consanguinidade a que pertencem esses indivíduos, compartilham o mesmo espaço fisico, estabelecendo interações sociais de qualquer natureza". E, neste contexto, o envelhecimento populacional tem provocado o surgimento de novas configurações familiares, dentre estas, as familias intergeracionais marcadas pela corresidência, que se refere à convivência entre idosos, filhos e/ou netos no mesmo espaço domiciliar (CAMARANO et al., 2004). 
A corresidência entre familiares reflete uma convivência em família de forma variada, devido aos acontecimentos familiares e mudanças por razões diferentes, que vão desde a escassez de recursos financeiros até a necessidade de cuidados por um parente idoso dependente. Essa convivência caracteriza-se por configurações instáveis, de contornos variados, que se fazem e desfazem em função desses acontecimentos (AGUIAR, 2007).

Nos países desenvolvidos, a corresidência dos idosos com seus familiares não é uma realidade. Em países como Estados Unidos, Canadá, Grã-Bretanha e Dinamarca, a maioria dos idosos vive sozinha ou apenas com seus cônjuges, os chamados "ninhos vazios", porém em países marcados pela pobreza, a corresidência com filhos e netos surge como uma estratégia de sobrevivência mútua (CAMARANO et al., 2004; TEIXEIRA; RODRIGUES, 2009).

Para o idoso, dois fatores são determinantes da sua corresidência: as suas condições de saúde e a sua renda financeira. Porém, dentre esses determinantes, a renda é apontada como um dos principais fatores da corresidência, visto que, em alguns casos, o idoso pode sofrer de necessidades financeiras e, em outros, a renda recebida pelos idosos poderia atrair familiares com condições financeiras precárias (PAULO; WAJNMAN; OLIVEIRA, 2013).

Em relação aos filhos adultos, a corresidência com os idosos acontece porque muitos continuam morando na casa dos pais, devido às dificuldades na inserção no mercado de trabalho e/ou na constituição de uma nova família, revelando um quadro de dependência em relação aos idosos. Há também os casos onde filhos voltam às casas dos pais após separações e divórcios, ou retornam à família de origem com mulher e filhos por questões financeiras.

A literatura brasileira tem destacado a importância da renda do idoso no sustento das famílias por meio das aposentadorias (AREOSA; AREOSA, 2008; VIEIRA; RAVA, 
2012). Os dados do Instituto de Pesquisa Econômica Aplicada (IPEA) apontam que a renda média dos maiores de 60 anos é superior à dos jovens, bem como a proporção de chefes idosos residentes em casa própria. Os dados reforçam essa tendência, quando apontam que a taxa de participação econômica dos jovens entre 15 e 24 anos apresentou uma queda expressiva entre 2009 a 2012 (IPEA, 2013).

Nesse contexto, a corresidência traz diversos beneficios aos idosos e a seus familiares, uma vez que proporciona compartilhamento de bens e renda, além de trocas de cuidados e assistência. Chama-se atenção de que muitos dos idosos no papel de avós proporcionam cuidados aos seus netos adolescentes e crianças, enquanto os filhos trabalham ou realizam atividades fora do contexto familiar, ou seja, o idoso torna-se provedor também de apoio afetivo e de educação para os seus netos (OLIVEIRA; VIANNA; CÁRDENAS, 2010).

Entretanto, a convivência familiar muitas vezes pode ser marcada por instabilidades e conflitos nas relações que podem gerar possiveis violências e maus tratos, o que não garante uma velhice bem-sucedida, nem relações amorosas entre seus entes. O dilema que a família pode enfrentar pelas instabilidades reflete, em muitos casos, o questionamento de normas e valores que antes eram aceitos e que, no momento em que são interrogados, revelam divergências tanto pelos pais quanto pelos filhos (CAMARANO et al., 2004; ARANTES et al., 2010).

Nesse sentido, o convivio familiar no âmbito da corresidência é um ponto importante a ser considerado pelos profissionais da saúde em relação aos idosos e sua família, pois se, por um lado, o convívio pode trazer consigo desentendimentos, por outro, pode ser considerado um processo de trocas mútuas, onde todos compartilham apoio, cuidado e assistências. Torna-se importante, assim, a realização de pesquisas científicas que busquem uma visão ampliada sobre família desde as relações familiares para 
idosos em corresidência, buscando informações sobre os aspectos subjetivos como o sentimento dos idosos em relação a conviver com diversas gerações da família.

\section{Cenário do estudo e metodologia}

A corresidência, ou a ampliação das famílias, pode ser uma estratégia familiar empregada para beneficiar tanto as gerações mais novas quanto as mais velhas, embora sob formas diferenciadas (CAMARANO et al., 2004). Porém, em muitas situações, a corresidência não implica apenas beneficios com a presença de sentimentos afetivos entre os familiares e os idosos, mas também na ocorrência de conflitos intergeracionais.

O convivio de várias ou algumas gerações de uma mesma família faz com que sejam colocadas lado a lado diferentes ideias e visões de mundo que podem favorecer o conflito no seio familiar. Acrescenta-se ainda que a corresidência pode não ser um arranjo familiar almejado por todos os idosos, visto que estes possuem dificuldades a adaptações, ou seja, não se sabe se esses arranjos refletem as preferências por sentimentos de amor e carinho ou se a corresidência acontece puramente por questões socioeconômicas e de saúde (LEITE et al., 2012).

A partir destas considerações, emerge a necessidade de se estimular pesquisas que busquem delimitar como objeto de estudo as significações sobre família construídas sob as relações familiares dos idosos em corresidência, não na perspectiva puramente social, mas dando ênfase a uma visão subjetiva, conforme é representada e (res) significada. Diante deste cenário, neste estudo buscou-se discutir as significações decorrentes das relações estabelecidas entre idosos e familiares em estado de corresidência, identificadas a partir de pesquisa realizada em um município do interior do estado da Bahia. 
Trata-se de um estudo fundamentado na Teoria das Representações Sociais, de caráter qualitativo, descritivo e exploratório, realizado com idosos cadastrados na área de abrangência de duas Unidades de Saúde da Família (USF) na área urbana. Os idosos corresidiam em lares intergeracionais (uma ou mais gerações), pertencentes à faixa etária de 60 anos ou mais e com grau de cognição suficiente para responder aos instrumentos de produção dos dados, avaliados segundo os escores no Mini Exame do Estado Mental (MEEM), proposto pelo Ministério da Saúde.

O levantamento realizado através das fichas A nas Unidades evidenciou um total de 169 idosos em estado de Corresidência. A estratégia para produção dos dados foi realizada durante os meses de fevereiro a maio de 2014 e ocorreu junto a cada idoso, individualmente, em seu domicílio por meio do auxílio dos Agentes Comunitários de Saúde (ACS). Realizaram-se as entrevistas por meio de um instrumento para coleta dos dados sociodemográficos, contendo uma questão norteadora que buscava compreender as dimensões dos sentimentos dos idosos em relação a conviver com sua família, com registro feito por um gravador eletrônico. Posteriormente, as respostas foram transcritas na integra.

Após a aplicação dos critérios de exclusão de participantes inicialmente estabelecidos, dos 169 idosos identificados, foram realizadas entrevistas junto a 80 idosos, gerando a base de dados que deu origem ao estudo. A análise dos dados resultantes da questão norteadora ocorreu a partir de duas estratégias: a partir da Técnica de Análise de Conteúdo Temática, estabelecida em Bardin (2011), utilizando-se de um total das entrevistas realizadas com 40 participantes, obedecendo ao critério de saturação dos dados; através da aplicação do modelo para análise cognitiva de representações sociais intitulado de AnCo-REDES, estabelecido em Lopes (2014), utilizando-se, nesse caso, todo o conjunto das entrevistas realizadas, no total de 80 idosos. 


\section{Estudo das relações estabelecidas entre idosos e familiares por meio da técnica de análise de conteúdo temática}

A Técnica de Análise de Conteúdo caracteriza-se por uma descrição analítica conforme procedimentos sistemáticos e objetivos de descrição do conteúdo da narrativa da entrevista, estrutura-se em três etapas: a pré-análise, a exploração do material ou codificação e o tratamento dos resultados, inferência e interpretação (BARDIN, 2011).

Dentre os participantes do estudo, $75,00 \%$ dos idosos eram do sexo feminino e em relação à faixa etária, $52,5 \%$ encontravam-se na faixa etária entre 60 a 70 anos. A análise do conjunto dos depoimentos, realizada por meio de elementos da Técnica de Análise de Conteúdo Temática (BARDIN, 2011), gerou duas categorias principais: Relações familiares marcadas pelo sentimento da harmonia; Relações familiares marcadas pelo sentimento da preocupação. As duas categorias sintetizam a relação familiar na percepção do idoso.

\section{Relações familiares marcadas pelo sentimento da harmonia}

Na primeira categoria, foram observadas relações familiares marcadas pelo sentimento da harmonia, com a presença do bem-estar e equilíbrio entre os seus membros. A corresidência dos idosos com seus familiares favorece a presença de relações intensas com várias gerações de uma mesma família. Além disso, nessa fase da vida, a presença de limitações pelo aumento de doenças crônicas degenerativas faz com que os idosos necessitem de maior suporte familiar, o que leva ao maior convivio com os mesmos e, consequentemente, ao fortalecimento dos laços afetivos entre seus membros. 
As falas de três entrevistados relatam relações familiares permeadas pelo bem-estar, harmonia e equilíbrio.

- A minha família, eu convivo muito bem! [...] Graças a Deus, eu me sinto bem com a minha família (I11).

- Bem. Não tenho nada contra a dizer da minha família. Vivo bem, nunca tive desarmonia com ninguém, discussão com ninguém, vive tudo bem aqui dentro de casa. Eu sinto bem (I33).

- Eu me sinto bem, viver com minha família [...] Com meus netos, com meus filhos, com minhas noras. Então pra mim, eu não tenho o que falar da família! (I30).

O suporte familiar, decorrente, muitas vezes, da necessidade do idoso, resulta em efeitos emocionais positivos, além dos sentimentos de pertencimento e estima pelos idosos em relação aos seus familiares. A percepção da presença do cuidado familiar está relacionada à competência social, capacidade de enfrentar problemas, senso de tranquilidade, afeto e, consequentemente, bem-estar psicológico (INOUYE, 2010).

Apesar das mudanças ocorridas nas famílias, elas ainda são fonte de amor e carinho para seus membros, independentemente de qualquer dificuldade ou problema. Pode-se considerar família uma unidade social, onde todos os seus membros estabelecem relações entre si e o mundo exterior, desempenhando funções importantes como o afeto, a educação, o cuidado e a sociabilização.

Sendo assim, a família contribui no sistema como um todo. O suporte familiar para os idosos tem importância crucial, pois através do convivio se sentem valorizados e amados. A família que possui uma atmosfera harmoniosa entre as pessoas favorece o cuidado entre os membros e um crescimento de todos, inclusive o idoso, onde as diferenças de ideias de cada membro são respeitadas. Entretanto, quando o contrário acontece, surgem relacionamentos de frustração e tristeza, gerando o isolamento social deste idoso (DIAS, 2011). 


\section{Relações familiares marcadas pelo sentimento de preocupação}

Para alguns idosos participantes deste estudo, o convívio intergeracional pode gerar uma preocupação significativa com o bem-estar de todos os membros da família, existindo pensamentos relacionados à preocupação com a dependência financeira e emocional dos mais jovens, e das questões sociais relacionadas ao maior risco de violências, ao uso frequente do consumo de álcool e outras drogas por parte dos filhos ou netos. As falas de quatro idosos descrevem essa preocupação em relação aos membros de sua família.

- Mesmo ele me fazendo companhia é bom, mas eu só gostaria que ele construísse uma familia, tivesse a mulher dele, os filhos dele, a família dele. Que eu dou meu jeito de companhia; eu daria outro jeito e passaria [...] Eu acho que ele tem que cuidar da vida dele!(I2).

- É às vezes ele bebe, aí eu me preocupo, aí eu fico preocupada [...]. Só a minha preocupação é essa. Quando está bebendo, bebe demais, ai eu [...]a gente fica preocupada. [...] Às vezes bebendo, a gente fica com medo às vezes de ter uma confusão, fica mais agitado, mas o resto a gente vive bem graças a Deus! (I8).

- [...] Quero um emprego pra ele, que ele está desempregado [...] (I10).

- [...] Só o problema é esse que eu te participei [...] Que ele usa droga e está num centro de recuperação, somente (I24).

As mudanças ocorridas na família, bem como a falta de políticas públicas voltadas para idosos e seus familiares, têm fortalecido a necessidade econômica da corresidência com múltiplas gerações, sendo considerado um arranjo familiar criado como uma estratégia de sobrevivência e economia de custos entre seus membros. Isso tem ocorrido, principalmente, devido aos altos indices de desemprego e das instabilidades emocionais, que favorecem a permanência dos filhos ou o retorno para a casa 
dos pais, mantendo-se, assim, o idoso ou a idosa como os provedores do lar (CAMARANO et al., 2004).

No contexto da pobreza, os idosos, muitas vezes, são os únicos colaboradores do orçamento doméstico. Para os idosos, a falta de independência financeira de filhos e/ou netos provoca um sentimento de preocupação com o convivio e o bem-estar dos familiares, o que leva muitos idosos a buscarem na informalidade a complementação da renda doméstica.

Estudo realizado em Minas Gerais identificou um número relevante de idosos que coabitam com netos e filhos, sendo os netos a geração mais prevalente. Analisa ainda que a corresidência com idosos surge como único apoio para os membros familiares e solução para a falta de recursos econômicos (MEIRA, 2013).

Outra preocupação citada nas falas dos idosos refere-se à presença de álcool e outras drogas entre os filhos ou netos no seio familiar. Para muitos idosos, o convivio com drogas é algo recente e não faz parte de suas vidas em tempos anteriores, tornando dificil a adaptação a esse novo contexto social.

O refúgio nas drogas e o abuso da bebida ocorrem em detrimento das condições de desemprego dos jovens, que se somam às condições de pobreza e a impossibilidade destes de integração social (BERNARDY; OLIVEIRA, 2010). Um estudo que analisou a concepção dos familiares sobre os maus-tratos com os idosos no domicílio relata que a utilização de álcool e outras drogas pelos membros familiares favorece o risco para a ocorrência de agressões e violências no contexto familiar do idoso (SANTOS; LEITE; HILDEBRANDT, 2008).

O conflito, além de existir pela convivência com as drogas, ocorre também pelas diferenças de valores sociais e culturais entre as gerações, presentes entre o idoso e seus familiares, como também entre os próprios familiares. A fala de um idoso demonstra a presença desse conflito. 
- [...] Quando eu dou um tapa nela, muitas horas ela fala que quando completar 18 anos ela vai embora [...] eu sou vó dela, e muitas horas eu estou achando que ela tá errada e eu não quero bater, mas eu vou falar com ela e ela me responde com a maior mal criação [...] (I1).

Os conflitos, independentes da origem e fatores associados, podem provocar tensões psicológicas e sociais, que aumentam a velocidade de deteriorações associadas ao processo de envelhecimento, ou seja, a existência de corresidência com familiares não pode ser necessariamente vista como garantia de uma velhice bem-sucedida, nem o fato de morarem juntos como um sinal de relações amistosas entre idosos, filhos e netos. Essas tensões e preocupações podem influenciar no estado de saúde dos idosos (DIAS, 2011).

\section{Análise dos significados e relações que ocor- rem entre idosos e familiares por meio do mo- delo AnCo-REDES}

O AnCo-REDES é um modelo para análise cognitiva de representações sociais com base em redes semânticas. A estrutura do modelo é composta por elementos que são utilizados para a identificação da estrutura e análise do conteúdo das representações sociais, com base na Teoria do Núcleo Central (ABRIC, 1993; SÁ, 1996). Entretanto, neste estudo, utilizou-se, especificamente, do "grupo de sentido" (GS), que objetiva "contribuir para a análise do conteúdo das representações sociais e da descoberta das diferentes significações atribuídas pelo grupo social ao objeto em análise" (LOPES, 2014, p. 80). A partir dos grupos de sentido no modelo AnCo-REDES, foram geradas categorias para auxiliar na análise cognitiva do conteúdo das representações sociais identificadas.

Um grupo de sentido no modelo AnCo-REDES é gerado a partir da detecção dos elementos (vértices na rede 
semântica) que estejam densamente conectados com vértices que integrem diferentes comunidades (subconjunto de vértices, ou seja, sub-redes) esparsamente conectadas. Maiores detalhes sobre o modelo podem ser encontrados em Lopes (2014). Na base utilizada para este estudo, foram identificados seis grupos de sentido: GS1 - relações intergeracionais marcadas pelo amor, cuidado e apoio no convivio em família; GS2 - relações intergeracionais marcadas por um bom viver; GS3 - convivência intergeracional marcada pela união entre familiares; GS4 - convivência entre familiares como suporte para resolução de problemas; GS5 - relações intergeracionais marcadas pela fé, paciência e orientação a familiares; GS6 - relações intergeracionais marcadas por conflitos e solidão.

O grupo de sentido Relações Intergeracionais Marcada pelo Amor, Cuidado e Apoio no Convivio em Família (GS1) retrata as interações entre idosos e familiares que ocorrem motivadas por um cuidar e ser cuidado, não apenas pela necessidade de ajuda, mas pela satisfação, por se sentir útil. Os vértices (termos) que mais se destacam nesse grupo são: cuidado, amor, apoio e bem, os quais têm sido característicos na maioria das falas. Nesse sentido, destacam-se as falas de três idosos que demonstram a presença dessas relações.

- Amor. Eu não passo sem minha família, é neta, mas eu considero como minha filha, é quem cuida de mim, que faz tudo por mim [...] (I54).

- A minha família, eu convivo muito bem! Porque eu moro aqui com três filhos homens, eles é quem faz as coisas, que faz a comida pra mim. Até o dia que eu não guento ir no banheiro, eles me leva, me dá banho. Umas ótimas pessoas pra mim! Trata tudo a hora certa! [...] Graças a Deus, eu me sinto bem com a minha família (I11).

- Meu sentimento é um sentimento de amor, de ajudar, de participar assim com eles enquanto eu tiver vida, e eu estiver lúcida. Eu quero ajudar, eu ainda me sinto assim útil, quero ser útil até o momento que eu estiver com essa vida [...] enquanto eu puder ajudar, eu quero estar junto a eles, ajudando, sendo útil como eu já falei [...] (I62). 
No grupo de sentido Relações Intergeracionais Marcadas por um Bom Viver (GS2), percebe-se uma significação específica dentro do contexto analisado em que, para o idoso, é bom poder viver com os familiares. Na fala do idoso I33, é possivel perceber essas relações presentes nas representações sociais deste grupo de idosos, identificadas no GS2.

- Bem. Não tenho nada contra a dizer da minha família. Vivo bem, nunca tive desarmonia com ninguém, discussão com ninguém, vive tudo bem aqui dentro de casa. Eu sinto bem (I33).

O grupo de sentido Convivência Intergeracional Marcada pela União entre Familiares (GS3) retrata a existência de uma interação satisfatória entre idosos e seus familiares, o que leva a um "querer estar junto", a um sentimento de entreajuda nas dificuldades. Entretanto, mesmo tendo a necessidade, um desejo de estar junto, o idoso se preocupa com o fato do seu familiar ficar preso a ele, e não construir a sua própria família. Nesse grupo, o vértice que mais se destaca é convivência, seguido de união e construir família. A fala do idoso I2 possibilita a percepção da presença dessas relações nas representações sociais dos participantes da pesquisa, que podem ser identificadas no GS3.

- Não tenho o que reclamar me sinto bem! Tanto com a pessoa que vive comigo dentro de casa, o meu filho que tem 34 anos. Mesmo ele me fazendo companhia é bom, mas eu só gostaria que ele construisse uma família, tivesse a mulher dele, filhos dele, a família dele. Que eu dou meu jeito de companhia, eu daria outro jeito e passaria, entendeu? Eu acho que ele tem que cuidar da vida dele (I2).

Neste estudo também foram identificadas relações que marcam uma convivência familiar pela necessidade de resolução de problemas, identificadas no GS4 (convivência entre familiares como suporte para resolução de problemas). Dessa forma, é possivel perceber uma significação 
sobre as relações familiares que difere das demais, mas que está presente nas representações dos idosos participantes da pesquisa, ou seja, uma relação pautada na importância do idoso como provedor, como suporte para solução de problemas (e. g. problemas financeiros). A aposentadoria do idoso, muitas vezes, é a única fonte de renda da família. As falas de dois idosos merecem destaque por demonstrar essas relações encontradas.

- É o desprezo, é só procurar quando necessita de alguma coisa, fora isso parece que não existe, sabe? Mas se precisa bate na porta. E outra coisa, se não tiver no momento para servir, ou não puder fazer nada naquele momento, é pior, porque fica até de mal, fica aborrecida e para de procurar, para de telefonar, para até esquecer e começar tudo novamente. Pra mim só o desprezo é que acaba comigo (I65).

- Meu sentimento é... que eu penso nesse sentido, é porque (como é que se diz) no momento assim aí Deus me levar e eles (como é que se diz), precisa de mim, né? Então... é uma coisa que meu sentimento é esse de ficar aí, né? E um sem ter (como é que se diz) da onde buscar as coisas, né? Então (como é que se diz) aqui dentro de casa só é eu que tenho... ela tá sem trabalho, tudo enfim. Aí meu pensamento é esse que eu penso (I47).

Com o grupo de sentido Relações Intergeracionais Marcadas pela Fé, Paciência e Orientação a Familiares é possivel perceber que, para o idoso, a fé é algo presente nas suas relações familiares, e é nela que muitas vezes busca alento, paciência, principalmente para lidar com as dificuldades do seu cotidiano, como o uso de drogas por membros da familia. O apoio aos filhos e netos é importante para o idoso, e um papel de orientador, conselheiro, educador também é exercido por ele nas interações familiares. Percebe-se ainda que essas preocupações fazem parte do cotidiano do idoso em estado de corresidência, e as politicas públicas devem levar essa realidade em consideração. As falas de três idosos, participantes da pesquisa, demonstram essas relações encontradas a partir da análise deste grupo de sentido. 
- Meu relacionamento é muito bom, graças a Deus, né? Tem hora que a gente passa a hora assim... de angústia que a gente tá na idade, né? Não tem paciência, mas Deus tá me dando paciência pra lidar com ele. Eu creio que Deus vai me dar paciência pra mim tá com ele diariamente (I14).

- Bom, o sentimento que eu tenho é que eu sou vó dela e muitas horas eu tô achando que ela tá errada e eu não quero bater, mas eu vou falar com ela e ela me responde com a maior mal criação... [...] Até que eu falo com ela que ela vai ver qual é a estrada mais perto pra ela. Ou morar dentro de casa com a vó, ou ir pra rua [...] Eu não ando batendo nela, eu não ando judiando dela, eu só não deixo ela sair bestando. O dela daqui pra escola e da escola pra aqui. Só. Eu não deixo ela ir pra casa das amigas dela por aí bestar, pro nome dela não ficar pela rua. Só isso. (I1)

- [...] Aí eu dou conselho a ele como uma mãe mesmo pode dar conselho para um filho, pra nós viver mais em camaradagem. [...] Eu amo meu filho, gosto muito, eu converso com ele, falo tanto com ele e ele - 'O mãe, eu amo a senhora, quero bem a senhora [...] deixa que com fé em Deus vou sair dessa vida de fumar essas bestagens, eu não quero que a senhora passa mal por minha causa e nem sofrer por mim, porque eu amo a senhora, eu the quero bem, calma deixa de bestagem'. Então eu amo meu filho, adoro ele, que ele é meu caçula. [...] só o mal é isso, que eu converso com ele e ele não atende quando eu falo (I69).

Com o grupo de sentido Relações Intergeracionais Marcadas por Conflitos e Solidão (GS6) percebe-se que, muitas vezes, o convívio familiar não é desejado pelo idoso, e isso ocorre em virtude dos conflitos existentes nas interações familiares. Entretanto, também existe o desejo pela harmonia na família, que leva o idoso a um agir tolerante, buscando intermediar as relações conflituosas. O idoso se sente responsável por sua família. Essa significação pode ser demonstrada a partir das falas de quatro idosos que integram a base de dados analisada.

- É isso que eu falei, eu quero mais é viver sozinho, a perturbação tá demais [...] dá muita briga, aqui a gente se enraiva, né? A gente tá é doido. Não quer ir embora [...] moleque 
de vinte e poucos anos perturbando dentro de casa (I44).

- Olha, o meu sentimento é porque eu tenho os dois filhos que mora mais eu, que eu já falei, e eu não fico satisfeita deles ter essa má união um com com outro, com outros, com ele mesmo, né? Então não é o caso de eu viver satisfeita, porque uma mãe ter os seus filhos dentro de casa pra viver eles com aquela má vivência um com os outros [...] (I6).

- Eu sinto minha filha ir embora, me largar. Eu sinto ... doença. Eu sinto morrer e ficar tudo aí. Deixo ver que mais... penso em saúde. Penso em... deixa eu ver... Penso assim... em qualquer coisa assim... eu ficar só... morar só... penso em solidão. Penso em meu esposo espairecer, ficar só. Penso em minha neta. Penso em todo mundo (I5).

- Me pegou. Eu me sinto assim...porque... Eu me sinto como uma advogada, porque cada um age de maneira diferente. Um é espontâneo, outro é calado. Aquele que é espontâneo acha que... aquele que é espontâneo, o que é mais calado, acha que o espontâneo tá pirraçando ele, aí gera um conflito, né? Tem um adolescente que às vezes fica até meia noite assistindo televisão, dorme o dia todo. Quando a gente vai reclamar, acha que a gente... abusada. É abusada, porque sempre pro jovem a gente que é de idade, que tem experiência, que vai dar conselho que a gente é abusada né? Então eu me sinto assim como uma advogada prá tá entendendo cada um de uma maneira diferente. [...] E dificil minha filha. [...] É por isso que eu falo assim, família é uma responsabilidade muito grande e a gente pra viver na harmonia a gente tem de tolerar muita coisa, engolir muita coisa, e às vezes pensa assim: 'Tá com medo', nõ tá com medo não, é procurar entender cada um de sua maneira (I17).

A análise do conteúdo das representações sociais a partir dos grupos de sentido que compõem o modelo AnCo-REDES possibilita ao analista tanto um olhar global para as representações, quanto também para aquelas significações individuais, locais, identificadas nas representações sociais através dos vértices da rede e as conexões estabelecidas entre eles. Com a Figura 1 é possivel fazer uma inspeção visual das sub-redes equivalentes aos grupos de sentido resultantes da aplicação do AnCo-REDES na base de dados estudada e, desta forma, melhor compreender as 
relações que ocorrem entre os diversos termos (vértices) que emergem da rede de significados extraida das entrevistas junto aos idosos participantes da pesquisa.

FIGURA 1 - Grupos de Sentido (sub-redes) identificados ao aplicar o modelo AnCo-REDES na base de dados gerada a partir das entrevistas realizadas junto a 80 idosos em estado de corresidência

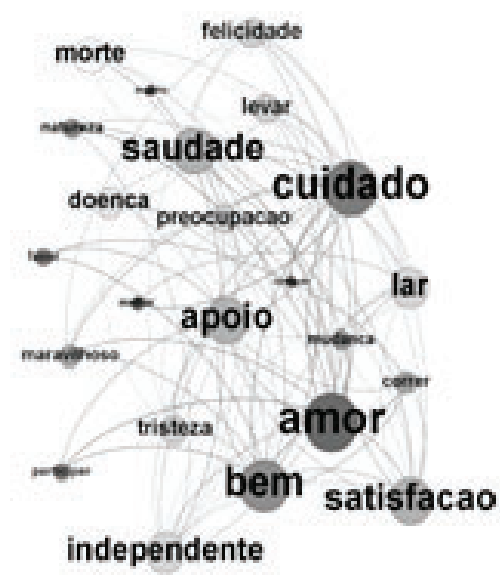

1(a) Sub-rede do Grupo de Sentido "relaçōes intergeracionais marcada pelo amor, cuidado e apoio no convivio em familia". (GS1)

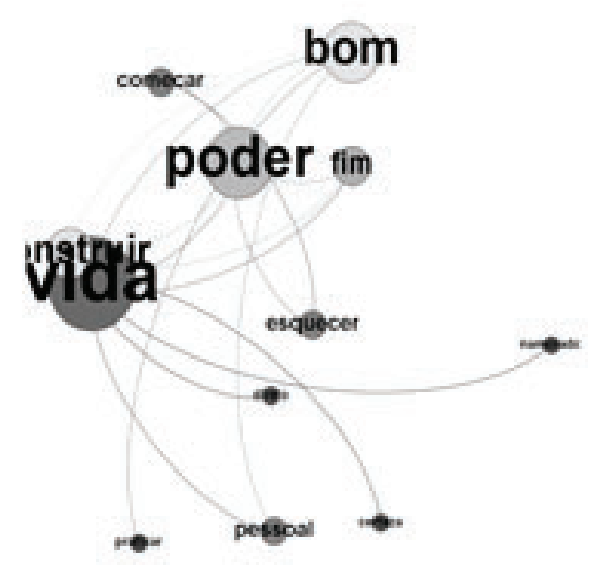

1(b) Sub-rede do Grupo de Sentido "relaçōes intergeracionais marcada por um bom viver" (GS2) 
FIGURA 1 - Grupos de Sentido (sub-redes) identificados ao aplicar o modelo AnCo-REDES na base de dados gerada a partir das entrevistas realizadas junto a 80 idosos em estado de corresidência

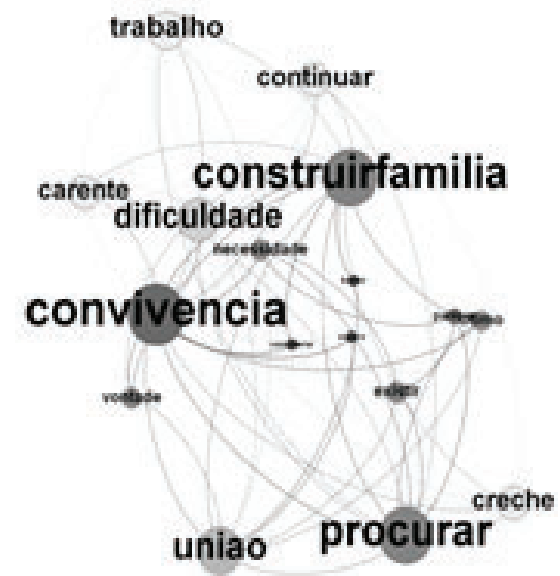

1(c) Sub-rede do Grupo de Sentido

"convivéncia intergeracional marcada pela uniăo entre familiares". (GS3)

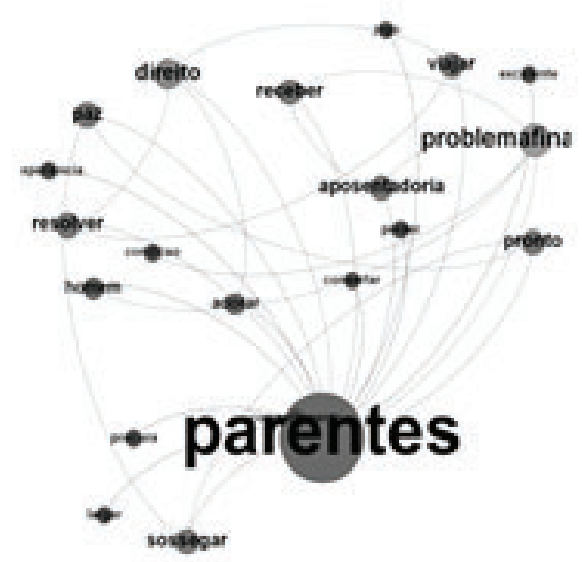

1 (d) Sub-rede do Grupo de Sentido convivéncia entre familiares como suporte para resoluçăo de problemas". (GS4)

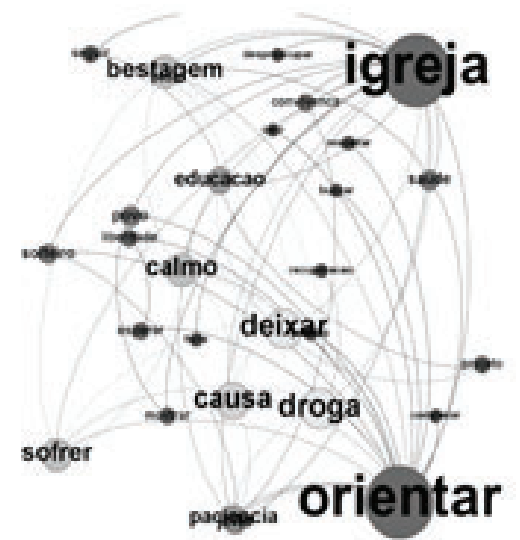

1(e) Sub-rede do Grupo de Sentido "relaçōes intergeracionais marcada pela fé, paciéncia e orientaçāo a familiares" (GS5)

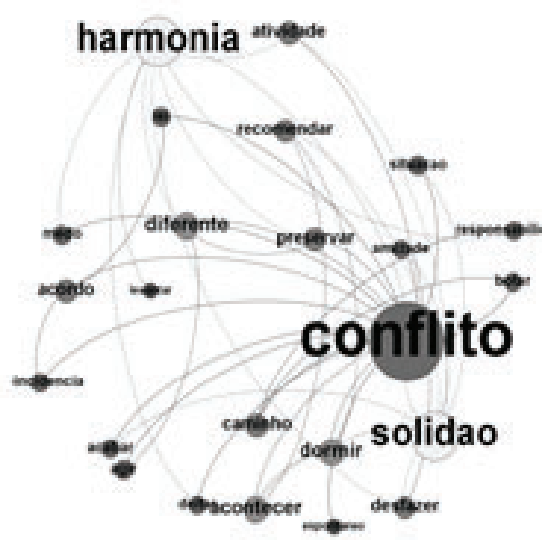

1 (f) Sub-rede do Grupo de Sentido "relaçōes intergeracionais marcada por conflitos e solidảo" (GS6)

Fonte: Adaptado de Lopes (2014) 


\section{Considerações finais}

Os resultados deste estudo, obtidos tanto pela Técnica de Análise de Conteúdo Temática quanto pela análise a partir do modelo AnCo-REDES, demonstram que as relações familiares dos idosos em corresidência são marcadas por sentimentos de harmonia, bem-estar, amor, união e apoio, que resultam no fortalecimento dos laços afetivos e cuidados compartilhados pelos membros. O cuidado mútuo, ou seja, os idosos cuidados por familiares, e esses, sendo cuidados pelos idosos, demonstra que a corresidência baseia-se em uma solidariedade intergeracional.

Nota-se, porém, que em muitos convivios familiares existe o sentimento pelo idoso de preocupação com o bem- estar da família como um todo, devido às instabilidades financeiras, ao uso de álcool e outras drogas pelos mais jovens e pelas divergências de ideias e valores entre as diversas gerações, tudo isso pode favorecer a presença de conflitos no seio familiar.

O convivio familiar pode não ser um arranjo almejado por todos os idosos, uma vez que as tensões podem diminuir a sua qualidade de vida. É necessário o compartilhamento de responsabilidades entre a família, o Estado e a sociedade como um todo. Trata-se do incentivo à criação e extensão de programas de assistência e políticas públicas de saúde e sociais voltadas para a melhoria das condições de vida dos idosos e seus familiares. 


\section{Referências}

ABRIC, Jean Claude. Central System, Peripheral System: their functions and roles in the dynamics of social representations. Papers on Social Representations. Textes sur les ReprésentationsSociales (1021-5573), v. 2, n. 2, p. 75-78, 1993.

AGUIAR, J.E. A experiência da co-residência para idosas em familia intergeracional. 2007. Dissertação (Mestrado em Enfermagem) - Setor de Ciências da Saúde, Universidade Federal do Paraná, Curitiba, 2007.

ARANTES, R.C et al. Arranjos domiciliares e saúde dos idosos: um estudo piloto qualitativo em um município do interior de minas gerais. Texto para discussão $n^{\circ} 405$. Belo Horizonte: UFMG/Cedeplar, 2010.

AREOSA, S. V. C; AREOSA, A. L. Envelhecimento e dependência: desafios a serem enfrentados. Revista Textos \& Contextos, Porto Alegre, v. 7, n. 1, p. 138-150, 2008.

BARDIN, L. Análise de Conteúdo. Lisboa: Edições 70, 2011.

BERNARDY, C. C. F; OLIVEIRA, M. L. F de. O papel das relações familiares na iniciação ao uso de drogas de abuso por jovens institucionalizados. Rev. Esc. Enferm USP, v. 44, n. 1, p.11-7, 2010.

BRASIL. Ministério da Saúde. Estatuto do Idoso. 1. ed., 2. reimpr. - Brasília: Ministério da Saúde, 2003.

CAMARANO, A. A et al. Famílias: espaço de compartilhamento de recursos e vulnerabilidades. In: CAMARANO, A. A. Os Novos Idosos Brasileiros: Muito Além dos 60? Rio de Janeiro: IPEA, 2004, p. 137-65.

DIAS, M. O. Um olhar sobre a família na perspectiva sistémica - O processo de comunicação no sistema familiar. Gestão e Desenvolvimento, v. 19, p. 139-156, 2011. 
INSTITUTO DE PESQUISA ECONÔMICA APLICADA (IPEA). Sinopse do Censo Demográfico 2013. Disponivel em: <http://www.ipea.gov.br>. Acesso em: 17 set. 2013.

INOUYE, K et al. Percepções de suporte familiar e qualidade de vida entre idosos segundo a vulnerabilidade social. PsicolReflCrit, v. 23, n. 3, p. 582-592, 2010.

JEDE, M; SPULDARO, M. Cuidado do idoso dependente no contexto familiar: uma revisão de literatura. Revista Brasileira de Ciências do Envelhecimento Humano, v. 6, n. 3, p. 413-421, 2009.

LEITE, M.T et al. Idosos mais velhos no domicílio: a família como unidade de cuidado. Rev. pesqui. cuid. fundam., v. 4, n. 4, p. 2816-31, 2012.

LEONE, E. T.; MAIA, A. G.; BALTAR, P. E. Mudanças na composição das famílias e impactos sobre a redução da pobreza no Brasil. Economia e Sociedade., v. 19, n. 1, p. 5977, 2010.

LOPES, Claudia Ribeiro S. AnCo-REDES - MODELO PARA ANÁLISE COGNITIVA COM BASE EM REDES SEMÂNTICAS: uma aplicação a partir da abordagem estrutural das representações sociais. 2014. Tese (Doutorado em Difusão do Conhecimento). Programa de Doutorado Multiinstitucional e Multidisciplinar em Difusão do Conhecimento - DMMDC, com sede na Universidade Federal da Bahia - UFBA: Salvador, 2014.

MEIRA, S. S. Estudo de base populacional entre as condições sociais e autoestima de idosos mineiros corresidentes. 2013. Dissertação (Mestrado em Enfermagem e Saúde), Universidade Estadual do Sudoeste da Bahia, Jequié, 2013.

MONTEIRO, L. M; SENA, T. C. C. B. Análise socioeconômica dos arranjos familiares em um CRAS no município de Belém - PA: o papel do idoso no contexto familiar. Revista portal de Divulgação, n. 27, 2012. 
OLIVEIRA, A. R. V; VIANNA, L. G; CÁRDENAS, C. J. Avosidade: visões de avós e de seus netos no período da infância. Rev. bras. geriatr. Gerontol., v. 13, n. 3, 2010.

PAULO, M. A.; WAJNMAN, S; OLIVEIRA, A. M. C. H. A relação entre renda e composição domiciliar dos idosos no Brasil: um estudo sobre o impacto do recebimento do Benefício de Prestação Continuada. Rev. bras. estud. popul., v. 30, supl, 2013.

SÁ, Celso Pereira de. Representações Sociais: teoria e pesquisa do Núcleo Central. Temas em Psicologia, n. 3, p. 1933, 1996.

SANTOS, A. M; LEITE, M. T; HILDEBRANDT, L. M. Maustratos a idosos no domicílio: concepção de familiares. Rev. bras. geriatr. Gerontol, v. 11, n. 2, p. 209-221, 2008.

TEIXEIRA, S. M.; RODRIGUES, V. S. Modelos de família entre idosos: famílias restritas ou extensas. Rev bras geriatr.

Gerontol., v. 12, n. 2, p. 239-254, 2009.

TORRES, G. V et al. Relação entre funcionalidade familiar e capacidade funcional de Idosos dependentes no município de Jequié (BA). Rev. baiana saúde pública, v. 34, n. 1, p.1930, 2010.

VERAS, R. Envelhecimento populacional contemporâneo: demandas, desafios e inovações. Rev Saúde Pública., v. 43, n. 3, p. 548-554, 2009.

VIEIRA, A. C. S.; RAVA, P. G. S. Ninho cheio: perspectivas de pais e filhos. Psicologia: teoria e prática.,v. 14, n. 1, p. 8496, 2012.

VILELA, Alba Benemérita Alves, et al. Envelhecimento e Corresidência: entendendo a estratégia de sobrevivência em lares multigeracionais. In: REIS, Luciana Araújo dos et al. (Org.). Ensaios sobre o Envelhecimento. Vitória da Conquista: Edições UESB, 2013. 